Политика и общество $2(98) \cdot 2013$

А.А. Ваганов

\title{
ПРАВОВОЙ РЕЖИМ ВОЗДУШНЫХ СУДОВ КАК ПРЕДМЕТА ЛИЗИНГА
}

Аннотация: B статье рассматриваются отдельные аспекты лизинга воздушных судов. Автор исследует правовой режим воздушных судов, их понятие, правовые аспекты регистрации и сертификации воздушных судов, а также значение лизинга воздушных судов в Российской Федерации.

Особое внимание обращено на специфику режима использования объектов атомной энергии.

Ключевые слова: лизинг, воздушное судно, регистрация, сертификация, эксплуатаџия, гражданская авиаџия.

$\mathrm{C}$ последующим развитием рынка воздушных судов виды сделок будут также увеличиваться. Так, все большую актуальность приобретает лизинг (финансовая аренда) воздушных судов ${ }^{1}$.

В последнее время лизинг воздушных судов имеет большое значение в условиях повышения требований к условиям авиаперевозок гражданским транспортом, а также значительного удорожания воздушных судов в силу развития и активного внедрения современных технологий.

Необходимо отметить, что в последнее время вместо покупки воздушного судна заинтересованные авиаперевозчики используют новые и использовавшиеся ранее воздушные суда на основе соглашения о лизинге $^{2}$. Действительно, по сравнению с покупкой - лизинг более гибкая и экономичная форма, она значительно снижает бремя первоначальных затрат на содержание воздушного судна, открывает возможность пользоваться налоговыми и таможенными льготами, повышает оперативность в удовлетворении сезонного спроса на дополнительные рейсы.

В.Д. Бордунов также отмечает, что для авиакомпании-лизингополучателя выгода лизинга заключается в возможности эксплуатации воздушного судна необходимого типа и провозной емкости, не уплачивая сразу его полную стоимость, что позволяет без резких финансовых затрат расширить и обновить свой авиапарк. Для лизингодателя лизинг воздушного судна это выгодный способ вложения капитала и средство эффективного размещения свободных денежных ак-

\footnotetext{
${ }^{1}$ См.: Бевзюк Е.А. Комментарий к Федеральному закону от 14.03.2009 № 31-Ф3 «О государственной регистрации прав на воздушные суда и сделок с ними» (постатейный) // Подготовлен для системы КонсультантПлюс, 2010.

2 См.: Бордунов В.Д. Международное воздушное право: Учебное пособие. - М.: Авиабизнес, Научная книга, 2007.
}

тивов. Поскольку они инвестируются в имущество, то в отличие от денежного кредита снижается риск невозврата средств. Несомненная выгода лизинга для изготовителя воздушных судов, их продавца, состоит в возможности получить полную стоимость воздушного судна за счет посредника - лизинговой компании. Изготовитель берет на себя обязательство осуществлять техническое обслуживание воздушного судна, что очень выгодно лизингопользователю. Для него отпадет необходимость найма специальных работников для его текущего и профилактического ремонта, а сам изготовитель получает возможность оперативно выявлять производственные и конструктивные недостатки воздушного судна в процессе его эксплуатации лизингополучателем. Другой положительной стороной лизинга является активное и динамичное влияние на развитие рынка аренды воздушных судов, что позволяет расширять объем сбыта новых воздушных судов для их изготовителей.

В Российской Федерации правовые основы договора лизинга установлены в $\$ 6$ главы 34 Гражданского кодекса Российской Федерации и Федеральном законе от 29 октября 1998 г. № 164-Ф3 «О финансовой аренде (лизинге)» ${ }^{3}$.

В соответствии со ст. 2 указанного закона договор лизинга представляет собой договор, в соответствии с которым лизингодатель обязуется приобрести в собственность указанное лизингополучателем имущество у определенного продавца и предоставить лизингополучателю это имущество за плату во временное владение и пользование. Договор лизинга независимо от его срока заключается в письменной форме, что установлено п. 1 ст. 15 Федерального закона «О финансовой аренде (лизинге)».

\footnotetext{
${ }^{3}$ Федеральный закон от 29.10.1998 № 164-Ф3 «О финансовой аренде (лизинге)» // С3 РФ, 02.11.1998, № 44, ст. 5394
} 
Предметом лизинга могут быть любые непотребляемые вещи, в том числе транспортные средства. Предмет лизинга, переданный во временное владение и пользование лизингополучателю, является собственностью лизингодателя, что следует из ст. 11. Согласно ст. 19 Федерального закона «О финансовой аренде (лизинге)» договором может быть предусмотрено, что предмет лизинга переходит в собственность лизингополучателя по истечении срока договора или до его истечения на условиях, предусмотренных соглашением сторон.

Применительно к воздушному судну как объекту лизинга необходимо отметить, что в законодательстве правовой статус воздушного судна представляется наиболее разработанным по сравнению с иными транспортными средствами и заключением договора аренды, в том числе лизинга данных транспортных средств.

Так, Е.В. Вавилин отмечает, что ГК РФ не содержит обобщающего определения транспортного средства. Необходимость его описания имеется, и она отражена лишь применительно к некоторым видам транспортных средств в отраслевых транспортных нормативно-правовых актах, в частности в ст. 32 Воздушного кодекса РФ. Автор также отмечает, что, по его мнению, законодатель сознательно не охарактеризовал рассматриваемый объект гражданско-правовых сделок. Налицо полисистемный подход, заключающийся в том, что в конкретно рассматриваемой области необходимо узкоспециальное определение транспортного средства в целях отграничения от других видов транспортных средств и наиболее полного и совершенного правового регулирования 4 .

Как отмечено, определение воздушного судна содержится в ст. 32 Воздушного кодекса РФ5, согласно которой воздушным судном является летательный аппарат, поддерживаемый в атмосфере за счет взаимодействия с воздухом, отличного от взаимодействия с воздухом, отраженным от поверхности земли или воды.

Данное понятие копирует соответствующее определение воздушного судна из стандартов приложения 7 к Чикагской конвенции 1944 г., в соответствии

\footnotetext{
${ }^{4}$ См.: Вавилин Е.В. Осуществление прав и исполнение обязанностей по договору аренды транспортных средств. - М.: Волтерс Клувер, 2009.

${ }^{5}$ Воздушный кодекс Российской Федерации от 19.03.1997 № 60-Ф3 // С3 РФ, 24.03.1997, № 12, ст. 1383
}

с которым воздушным судном, летательным аппаратом называется любой аппарат, поддерживаемый в атмосфере за счет реакции воздуха, отличной от реакции воздуха с земной поверхностью.

При этом, только в 2006 году Федеральным законом «О внесении изменений в Воздушный кодекс Российской Федерации» ${ }^{6}$ в российское законодательство была введения классификация воздушных судов в зависимости от их веса.

Так, п. 2 ст. 32 Воздушного кодекса РФ определяет легкое воздушное судно как воздушное судно, максимальный взлетный вес которого составляет менее 5700 килограмм, в том числе вертолет, максимальный взлетный вес которого составляет менее 3100 килограмм, а сверхлегкое воздушное судно - воздушное судно, максимальный взлетный вес которого составляет не более 495 килограмм без учета веса авиационных средств спасания.

В класс сверхлегких попадает много воздушных судов единичного изготовления, в том числе самодельных, которые, естественно, не могут соответствовать общим требованиям, предъявляемым к воздушным судам для их регистрации в Государственном реестре гражданских воздушных судов РФ и удостоверения их летной годности. Используются такие воздушные суда, как правило, в авиации общего назначения ${ }^{7}$.

Необходимо отметить, что более широкое определение воздушных транспортных средств представлено в Федеральном законе «О государственном регулировании развития авиации» ${ }^{8}$, в соответствии со ст. 1 которого летательными аппаратами признаются самолеты, вертолеты, авиационные, авиационно-космические ракеты, аэростаты, дирижабли, планеры, автожиры, дельтапланы и другие летательные аппараты; летательные аппараты могут быть военными, специальными, гражданскими и экспериментальными. В то же время к авиационной технике относятся летательные аппараты, их бортовое оборудование и агре-

\footnotetext{
${ }^{6}$ Федеральный закон от 18.07.2006 № 114-Ф3 «О внесении изменений в Воздушный кодекс Российской Федерации» // С3 РФ, 24.07.2006, № 30, ст. 3290

7 См.: Комментарий к Воздушному кодексу Российской Федерации (постатейный) / В.Г. Ермошкин, С.И. Коровин, А.Н. Петров и др.; под ред. А.И. Травникова. - М.: Деловой двор, 2009.

${ }^{8}$ Федеральный закон от 08.01.1998 № 10-Ф3 «О государственном регулировании развития авиации» // С3 РФ, 12.01.1998, № 2, ст. 226
} 


\section{Политика и общество 2 (98) • 2013}

гаты, двигатели, авиационное вооружение, авиационные средства спасания, тренажеры, наземные средства управления воздушным движением, навигации, посадки и связи, а также средства наземного обслуживания летательных аппаратов.

Согласно ст. 33 Воздушного кодекса РФ воздушные суда, предназначенные для выполнения полетов, подлежат государственной регистрации в следующем порядке:

- $\quad$ гражданские воздушные суда, за исключением сверхлегких гражданских воздушных судов авиации общего назначения, - в Государственном реестре гражданских воздушных судов Российской Федерации с выдачей свидетельств о государственной регистрации или в государственном реестре гражданских воздушных судов иностранного государства при условии заключения соглашения о поддержании летной годности между Российской Федерацией и государством регистрации;

- $\quad$ сверхлегкие гражданские воздушные суда авиации общего назначения - в порядке, установленном уполномоченным органом в области гражданской авиации;

- $\quad$ государственные воздушные суда - в порядке, установленном уполномоченным органом в области обороны по согласованию с уполномоченными органами, имеющими подразделения государственной авиации.

При этом государственная регистрация гражданских воздушных судов Российской Федерации представляет собой документальное подтверждение государственным органом РФ распространения юрисдикции государства на данный экземпляр воздушного судна с вытекающими из этого обязательствами собственника, эксплуатанта и государства в соответствии с требованиями Воздушного кодекса РФ и международных соглашений ${ }^{9}$. За счет такой регистрации зарегистрированное в Российской Федерации воздушное судно приобретает национальную принадлежность Российской Федерации, так же как и приобретают национальную принадлежность воздушные суда в иностранных государствах.

В настоящее время государственная регистрация гражданских воздушных судов Российской Федера-

\footnotetext{
${ }^{9}$ См.: Симоненко А.М., Троицкая О.Н. Комментарий к Воздушному кодексу Российской Федерации (постатейный) // Подготовлен для системы КонсультантПлюс. 2007.
}

ции осуществляется в соответствии с Правилами государственной регистрации гражданских воздушных судов Российской Федерации ${ }^{10}$, и имеет своей задачей ${ }^{11}$ :

1. Учет всех гражданских воздушных судов Российской Федерации, совершающих полеты в воздушном пространстве РФ и за его пределами.

2. Определение национальности воздушного судна, т.е. принадлежности судна тому или иному государству.

3. Юридическое оформление права собственности, владения и эксплуатации данного воздушного судна.

4. Сосредоточение в органе государства сведений о гражданских воздушных судах.

В гражданской авиации согласно Чикагской конвенции 1944 г. надлежащая регистрация воздушного судна служит фундаментальной основой международных авиационных перевозок. Дополнительные подробности относительно регистрации и опознавательных знаков воздушных судов гражданской авиации содержатся в приложении 7 к Чикагской конвенции 1944 г: каждое воздушное судно должно быть зарегистрировано в одном из государств, и каждое государство должно вести реестр гражданских воздушных судов. Ни одно воздушное судно не может иметь действительной регистрации более чем в одном государстве, но возможна перемена регистрации от одного государства к другому. Государство регистрации каждого воздушного судна, внесенного в государственный реестр, берет на себя обязательства по обеспечению безопасной эксплуатации этого воздушного судна ${ }^{12}$.

Полеты незарегистрированных (неучтенных) воздушных судов не допускаются. Воздушные суда, не предназначенные для полетов (используемые, например, как памятники, учебные пособия), государственной регистрации (государственному учету) не

\footnotetext{
${ }^{10}$ Приказ Минтранса РФ от 02.07.2007 № 85 «Об утверждении Правил государственной регистрации гражданских воздушных судов Российской Федерации» // Бюллетень нормативных актов федеральных органов исполнительной власти, № 41, 08.10.2007

${ }^{11}$ См.: Вартанян Н.В. О порядке государственной регистрации гражданских воздушных судов // Транспортное право. - 2009. - № 3. - С. 24 - 26.

12 См.: Комментарий к Воздушному кодексу Российской Федерации (постатейный) / В.Г. Ермошкин, С.И. Коровин, А.Н. Петров и др.; под ред. А.И. Травникова. - М.: Деловой двор, 2009.
} 
подлежат. Особый порядок учета принимается для сверхлегких воздушных судов гражданской авиации общего назначения, метеорологических шаров-зондов и беспилотных неуправляемых аэростатов.

Следует отметить, что дополнительные правила по регистрации воздушных судов установлены в отношении государственных летательных аппаратов, которые подлежат государственной регистрации в соответствии с Федеральными авиационными правилами государственной регистрации государственных воздушных судов ${ }^{13}$. Данные правила устанавливают общий порядок государственной регистрации государственных воздушных судов, их учета в Государственном реестре государственных воздушных судов Российской Федерации по утвержденной форме. Правила являются обязательными для всех федеральных органов исполнительной власти и организаций, имеющих подразделения государственной авиации.

Гражданские воздушные суда регистрируются в соответствующем реестре, который ведется Федеральным агентством воздушного транспорта в установленном порядке в соответствии с Правилами государственной регистрации гражданских воздушных судов Российской Федерации.

Необходимо отметить, что при включении данных о гражданском воздушном судне в Государственный реестр органом регистрации присваиваются ему государственный и регистрационный опознавательные знаки, которые наносятся на гражданское воздушное судно (п. 30 Правил государственной регистрации гражданских воздушных судов Российской Федерации).

Без опознавательных знаков, нанесенных в соответствии с требованиями Правил на элементы конструкции гражданского воздушного судна, полеты не производятся. Одновременное нанесение на гражданское воздушное судно опознавательных знаков разных государств не допускается.

Следует отметить, что указанные Правила государственной регистрации гражданских воздушных судов РФ регламентируют вопросы регистрации самих воздушных судов, но не прав на них ${ }^{14}$.

\footnotetext{
${ }^{13}$ Приказ Министра обороны РФ от 28.11.2002 № 460 «Об утверждении Федеральных авиационных правил государственной регистрации государственных воздушных судов» // Бюллетень нормативных актов федеральных органов исполнительной власти, № 20, 19.05.2003.

${ }^{14}$ См.: Симоненко А.М., Троицкая О.Н. Комментарий к Воздушному кодексу Российской Федерации (постатейный) // Подготовлен для системы КонсультантПлюс. 2007.
}

В соответствии со ст. 131 ГК РФ порядок государственной регистрации прав на недвижимость и основания отказа в регистрации устанавливаются в соответствии с законом о регистрации прав на недвижимое имущество - Федеральным законом «О государственной регистрации прав на недвижимое имущество и сделок с ним» ${ }^{15}$. Однако в ст. 4 указанного Федерального закона предусмотрено, что он не распространяется на воздушные и морские суда, суда внутреннего плавания и космические объекты.

В настоящее время действует Федеральный закон «О государственной регистрации прав на воздушные суда и сделок с ними» ${ }^{16}$, согласно которому государственная регистрация прав на воздушные суда и сделок с ними является юридическим актом признания и подтверждения государством наличия, возникновения, перехода, прекращения, ограничения (обременения) права собственности и других вещных прав на воздушные суда в соответствии с Гражданским кодексом Российской Федерации.

При этом государственная регистрация прав на воздушные суда является единственным доказательством существования зарегистрированного права на воздушное судно. Зарегистрированное право на воздушное судно может быть оспорено только в судебном порядке.

Государственная регистрация прав на подлежащие государственной регистрации в соответствии с Воздушным кодексом Российской Федерации осуществляется на гражданские воздушные суда, а также на государственные воздушные суда, которые используются в коммерческих целях в порядке, установленном Правительством Российской Федерации.

Следует отметить, что внесение в Государственный реестр гражданских воздушных судов РФ сведений о собственнике судна не может считаться регистрацией права собственности. В пункте 3.6 Правил прямо указано, что акт регистрации воздушного судна не является актом регистрации сделки по отчуждению имущества, а свидетельство о регистрации гражданского воздушного судна не может удостоверять право собственности лица на соответствующее судно.

\footnotetext{
15 Федеральный закон от 21.07.1997 № 122-Ф3 «О государственной регистрации прав на недвижимое имущество и сделок с ним» // С3 РФ, 28.07.1997, № 30, ст. 3594

16 Федеральный закон от 14.03.2009 № 31-Ф3 «О государственной регистрации прав на воздушные суда и сделок с ними» // С3 РФ, 16.03.2009, № 11, ст. 1260
} 


\section{Политика и общество 2 (98) • 2013}

Согласно названным Правилам и сложившейся практике внесение изменений в свидетельство о регистрации гражданского воздушного судна в связи со сменой его собственника может быть произведено только по заявлению эксплуатанта судна. Заявление собственника, не являющегося одновременно эксплуатантом, не служит основанием для внесения в реестр записи о новом собственнике. Такой порядок, безусловно, нарушает интересы данной категории собственников. Дело в том, что любое заинтересованное лицо может получить информацию из реестра о собственнике воздушного судна. Такую информацию все, как правило, считают достоверной, поскольку она исходит из официального источника. Но если информация в реестре уже устарела, то у нового собственника воздушного судна могут возникнуть проблемы с доказыванием своих прав ${ }^{17}$.

При этом в П. 17 Правил установлено, что внесение изменений в Государственный реестр производится органом регистрации в следующих случаях:

- изменение собственника гражданского воздушного судна;

- изменение адреса собственника гражданского воздушного судна;

- изменение модификации (наименования) гражданского воздушного судна, связанное с его переоборудованием.

В случае изменения собственника гражданского воздушного судна или его адреса, непригодности к дальнейшему использованию свидетельства о регистрации, при изменении модификации (наименования) гражданского воздушного судна, связанного с его переоборудованием, органом регистрации производится замена свидетельства о регистрации.

Помимо государственной регистрации гражданские воздушные суда допускаются к эксплуатации при наличии сертификатов летной годности. Порядок их допуска к эксплуатации, в том числе на условиях аренды, устанавливается авиационными правилами (ст. 36). Воздушный кодекс предусматривает также сертификацию авиационных двигателей и воздушных судов, которая играет большую роль в защите права собственности и иных вещных прав, осуществляемой на основе международных договоров ${ }^{18}$.

${ }^{17}$ См.: Симоненко А.М., Троицкая О.Н. Комментарий к Воздушному кодексу Российской Федерации (постатейный) // Подготовлен для системы КонсультантПлюс. 2007

18 См.: Комментарий к Гражданскому кодексу Российской Федерации, части третьей (постатейный) / М.П. Бардина,
Сертификат летной годности (удостоверение о годности к полетам) выдается на основании сертификата типа (аттестата о годности к эксплуатации) или акта оценки конкретного воздушного судна на соответствие конкретного воздушного судна требованиям к летной годности гражданских воздушных судов и природоохранным требованиям. Использование гражданского воздушного судна, имеющего сертификат летной годности (удостоверение о годности к полетам), выданный на основании указанного акта оценки, для осуществления коммерческих воздушных перевозок не допускается.

При этом порядок выдачи сертификата летной годности (удостоверения о годности к полетам) утвержден в соответствующих Федеральных авиационных правилах «Экземпляр воздушного судна. Требования и процедуры сертификации» ${ }^{19}$.

Однако в целом допуск к эксплуатации государственных воздушных судов осуществляется в порядке, установленном Правительством Российской Федерации в Правилах допуска к эксплуатации государственных воздушных судов ${ }^{20}$, в соответствии с которыми допуск к эксплуатации государственного воздушного судна осуществляется после его изготовления в соответствии с нормативно-технической документацией до его ввода в эксплуатацию в установленном порядке, а также после его ремонта, связанного с выводом из эксплуатации государственного воздушного судна.

При этом на основании положительных результатов проведения проверочных мероприятий в формуляре государственного воздушного судна делается запись о годности к эксплуатации государственного воздушного судна, которая является основанием для допуска к эксплуатации государственного воздушного судна.

Необходимо отметить, что при лизинге воздушных судов возникает проблема обособления имущества (оборудования), передаваемого в аренду. При этом имеется в виду обособление не самого судна, а наиболее дорогостоящих его частей, например авиационных двигателей.

Б.А. Булаевский, Н.Г. Вилкова и др.; под ред. Н.И. Марышевой, К.Б. Ярошенко. - 3-е изд., испр. и доп. - М: КОНТРАКТ, ИНФРА-М, 2010.

${ }^{19}$ Приказ Минтранса РФ от 16.05.2003 № 132 «Об утверждении Федеральных авиационных правил «Экземпляр воздушного судна. Требования и процедуры сертификации» // Российская газета, № 116, 18.06.2003

${ }^{20}$ Постановление Правительства РФ от 12.09.2011 № 766 «О допуске к эксплуатации государственных воздушных судов» // С3 РФ, 19.09.2011, № 38, ст. 5386 
Согласно положениям Конвенции о международном финансовом лизинге ${ }^{21}$ правом, подлежащим применению к оборудованию, которое обычно перемещается из одной страны в другую, включая авиационные двигатели, является право государства, в котором находится основное коммерческое предприятие арендатора (ст. 7). Таким образом, норма, касающаяся авиационных двигателей, содержит иную коллизионную привязку, чем общая норма о воздушных судах. Правом, применимым к отношениям международного финансового лизинга, является - для воздушного судна, зарегистрированного в соответствии с Конвенцией о международной гражданской авиации, подписанной в Чикаго 7 декабря 1944 г., - право государства, в котором это воздушное судно было зарегистрировано ${ }^{22}$.

В Конвенции о международных гарантиях в отношении подвижного оборудования, подписанной в Кейптауне 16 ноября 2001 г., предусматриваются положения, направленные на защиту права собственности и иных вещных прав на подвижное оборудование.

В качестве вывода хотелось бы отметить, что несмотря на то, что в ближайшие годы Минфин России намерен увеличить расходы бюджета на поддержку авиастроения, причем основная часть этих средств будет направлена на субсидирование процентных ставок и поддержку лизинга для закупки самолетов российскими авиакомпаниями, рынок лизинга воздушных судов остается достаточно неразвитым и не совсем эффективным.

Полагаем, что для успешного развития данного сектора необходима государственная поддержка, которая может быть выражена как за счет прямой финансовой помощи, так и создании лизинговой компании с государственным участием на основе Объединенной авиастроительной корпорации для стимулирования лизинга отечественных воздушных судов.

\section{Библиография:}

1. Бевзюк Е.А. Комментарий к Федеральному закону от 14.03.2009 № 31-Ф3 «О государствен-

\footnotetext{
${ }^{21}$ Конвенция УНИДРУА о международном финансовом лизинге, заключена в Оттаве 28.05.1988 // СЗ РФ, 09.08.1999, № 32 , ст. 4040

22 См.: Комментарий к Гражданскому кодексу Российской Федерации, части третьей (постатейный) / М.П. Бардина, Б.А. Булаевский, Н.Г. Вилкова и др.; под ред. Н.И. Марышевой, К.Б. Ярошенко. - 3-е изд., испр. и доп. - М: КОНТРАКТ, ИНФРА-М, 2010.
}

ной регистрации прав на воздушные суда и сделок с ними» (постатейный) // Подготовлен для системы КонсультантПлюс, 2010.

2. Бордунов В.Д. Международное воздушное право: Учебное пособие. - М.: Авиабизнес, Научная книга, 2007.

3. Вавилин Е.В. Осуществление прав и исполнение обязанностей по договору аренды транспортных средств. - М.: Волтерс Клувер, 2009.

4. Комментарий к Воздушному кодексу Российской Федерации (постатейный) / В.Г. Ермошкин, С.И. Коровин, А.Н. Петров и др.; под ред. А.И. Травникова. - М.: Деловой двор, 2009.

5. Симоненко А.М., Троицкая О.Н. Комментарий к Воздушному кодексу Российской Федерации (постатейный) // Подготовлен для системы КонсультантПлюс. 2007.

6. Вартанян Н.В. О порядке государственной регистрации гражданских воздушных судов // Транспортное право. - 2009. - № 3. - С. 24 - 26.

7. Комментарий к Гражданскому кодексу Российской Федерации, части третьей (постатейный) / М.П. Бардина, Б.А. Булаевский, Н.Г. Вилкова и др.; под ред. Н.И. Марышевой, К.Б. Ярошенко. - 3-е изд., испр. и доп. - М: КОНТРАКТ, ИНФРА-М, 2010.

\section{References (transliteration):}

1. Bevzyuk E.A. Kommentariy k Federal'nomu zakonu ot 14.03.2009 № 31-FZ «O gosudarstvennoy registratsii prav na vozdushnye suda i sdelok s nimi» (postateynyy) // Podgotovlen dlya sistemy Konsul'tantPlyus, 2010.

2. Bordunov V.D. Mezhdunarodnoe vozdushnoe pravo: Uchebnoe posobie. - M.: Aviabiznes, Nauchnaya kniga, 2007.

3. Vavilin E.V. Osushchestvlenie prav $i$ ispolnenie obyazannostey po dogovoru arendy transportnykh sredstv. - M.: Volters Kluver, 2009.

4. Simonenko A.M., Troitskaya O.N. Kommentariy $\mathrm{k}$ Vozdushnomu kodeksu Rossiyskoy Federatsii (postateynyy) // Podgotovlen dlya sistemy Konsul'tantPlyus. 2007.

5. Vartanyan N.V. O poryadke gosudarstvennoy registratsii grazhdanskikh vozdushnykh sudov // Transportnoe pravo. -2009 . - № 3. - S. $24-26$. 